University of South Florida

DIGITAL COMMONS

Digital Commons @ University of

@ UNIVERSITY OF SOUTH FLORIDA

South Florida

Integrative Biology Faculty and Staff

Publications

Integrative Biology

$5-2008$

\title{
Food Restriction Compromises Immune Memory in Deer Mice (Peromyscus maniculatus) by Reducing Spleen-Derived Antibody- Producing B Cell Numbers
}

\author{
Lynn B. Martin \\ Ohio State University, Ibmartin@usf.edu \\ Kristen J. Navara \\ Ohio State University \\ Michael T. Bailey \\ Ohio State University \\ Chelsea R. Hutch \\ Ohio State University \\ Nicole D. Powell \\ Ohio State University \\ Follow this and additional works at: https://digitalcommons.usf.edu/bin_facpub \\ See next page for additional authors \\ Part of the Medical Sciences Commons
}

\section{Scholar Commons Citation}

Martin, Lynn B.; Navara, Kristen J.; Bailey, Michael T.; Hutch, Chelsea R.; Powell, Nicole D.; Sheridan, John F.; and Nelson, Randy J., "Food Restriction Compromises Immune Memory in Deer Mice (Peromyscus maniculatus) by Reducing Spleen-Derived Antibody-Producing B Cell Numbers" (2008). Integrative Biology Faculty and Staff Publications. 12.

https://digitalcommons.usf.edu/bin_facpub/12

This Article is brought to you for free and open access by the Integrative Biology at Digital Commons @ University of South Florida. It has been accepted for inclusion in Integrative Biology Faculty and Staff Publications by an authorized administrator of Digital Commons @ University of South Florida. For more information, please contact digitalcommons@usf.edu. 


\section{Authors}

Lynn B. Martin, Kristen J. Navara, Michael T. Bailey, Chelsea R. Hutch, Nicole D. Powell, John F. Sheridan, and Randy J. Nelson 


\section{Food Restriction Compromises Immune Memory in Deer Mice (Peromyscus maniculatus) by Reducing Spleen-Derived Antibody-Producing B Cell Numbers}

\author{
Lynn B. Martin II $^{1, *, \dagger}$ \\ Kristen J. Navara ${ }^{1, \star, \neq}$ \\ Michael T. Bailey ${ }^{2}$ \\ Chelsea R. Hutch ${ }^{1}$ \\ Nicole D. Powell ${ }^{2}$ \\ John F. Sheridan ${ }^{2}$ \\ Randy J. Nelson ${ }^{1}$ \\ ${ }^{1}$ Department of Psychology, Ohio State University, \\ Columbus, Ohio 43210; ${ }^{2}$ Department of Oral Biology, Ohio \\ State University, Columbus, Ohio 43210
}

Accepted 9/7/2007; Electronically Published 3/17/2008

\begin{abstract}
Immune activity is variable in many wild animals, despite presumed strong selection against immune incompetence. Much variation may be due to changes in prevalence and abundance of pathogens (and/or their vectors) in time and space, but the costs of immune defenses themselves may also be important. Induction of immune activity often increases energy and protein expenditure, sometimes to the point of compromising fitness. Whether immune defenses are expensive to maintain once they are generated, however, is less well appreciated. If so, organisms would face persistent challenges of allocating resources between immunity and other expensive physiological processes, which would mandate trade-offs. Mild food restriction $(70 \%$ ad lib. diet) reduces secondary antibody responses in deer mice (Peromyscus maniculatus), functionally representing a cost of immune memory. In this study, we asked whether compromised immune memory was mediated by a decrease in size of the B cell population responsible for producing antibodies (i.e., spleen-derived B lymphocytes producing immunoglobulin G $[\mathrm{IgG}])$. Two weeks of food restriction reduced total splenocytes, total splenic B lymphocytes (B220+ cells), and splenic B lym-
\end{abstract}

\footnotetext{
${ }^{*}$ These authors contributed equally to this work.

${ }^{\dagger}$ Corresponding author. Present address: Division of Integrative Biology, University of South Florida, 4202 East Fowler Avenue, Tampa, Florida 33620; email: lmartin@cas.usf.edu.

${ }^{\ddagger}$ Present address: Department of Poultry Science, 217 Poultry Science Building, University of Georgia, Athens, Georgia 30602.
}

Physiological and Biochemical Zoology 81(3):366-372. 2008. (C) 2008 by The University of Chicago. All rights reserved. 1522-2152/2008/8103-70542\$15.00 DOI: $10.1086 / 587090$ phocytes producing IgG (B220+/IgG + cells) but did not affect body mass or two circulating antibody subclasses (IgG1 and IgG2a) in deer mice. These results further indicate that maintenance of immune memory is expensive and may be subject to trade-offs with other physiological processes.

\section{Introduction}

The immune system protects organisms against infection, but this protection comes at a cost (Lochmiller and Deerenberg 2000). Activation of immune defenses, particularly induction of fever, increases calorie and protein turnover (Martin et al. 2003; Klasing 2004; Lee 2006). Such immune costs are often sufficiently large to affect fitness (Martin et al. 2008), including reductions in sexual ornament elaboration (Verhulst et al. 1999), rates of reproductive maturation (Fair and Myers 2002; Prendergast et al. 2004), and reproductive success (Ilmonen et al. 2000; Bonneaud et al. 2003). Whether maintenance of immune defenses imparts ongoing costs has received little attention. If it does, the costs of immune protection would be persistent, not just transient, and thus would impose larger constraints on other physiological processes (i.e., trade-offs) than is conventionally appreciated.

Until recently, the costs of maintaining immune defenses were thought to be modest (Klasing and Calvert 1999; Klasing 2004). For example, pharmacological reduction of circulating leukocyte numbers did not decrease whole-body energy turnover in white-footed mice (Peromyscus leucopus) as expected (Derting and Compton 2003). Similarly, metabolic rates of domesticated mice genetically engineered to lack $\mathrm{T}$ and $\mathrm{B}$ cells were higher, not lower, than those of outbred conspecifics (Råberg et al. 2002). Contrary to these studies, maintenance of antibody-mediated immune memory was found to be expensive in deer mice (Martin et al. 2007). Two weeks of mild food restriction (FR; 70\% of ad lib. [AL] consumption) prevented individuals from mounting secondary antibody responses, even though they were returned to AL food just before induction of secondary antibody responses. Restraint stress did not emulate or amplify FR effects on secondary antibody responses, indicating that FR effects were not mediated by increases in (potentially immunosuppressive) glucocorticoids (Martin et al. 2006). Functionally, compromised secondary antibody responses post-FR represent a cost of immune maintenance because the benefits of expending resources to generate immune 
memory (i.e., more rapid and targeted control of previously experienced infectious organisms) would not be realized in individuals experiencing food limitation.

Although a cost of maintaining the immune system was revealed in deer mice, the mechanism that produced this outcome was not identified. One viable possibility involves a post-FR decrease in the size of the cell population responsible for producing antibodies, specifically, spleen-derived B lymphocytes producing immunoglobulin $\mathrm{G}$ ( $\mathrm{IgG})$. To determine whether a change in B lymphocyte number post-FR was indeed the mechanism underlying the previous results, we generated immune memory in deer mice by exposing them to the same large immunogenic protein (keyhole limpet hemocyanin [KLH]) and FR paradigm as in the previous experiment and comparing antibody levels and number of splenic IgG progenitor cells among groups of deer mice. We predicted that FR would reduce both circulating antibody levels and splenic B cell numbers. Because some antibody isotypes (IgG2a) are more effective than others at promoting memory B cell proliferation, multiple antibody isotypes were measured (Klaus 1979). Also, because previous studies with deer mice indicated that day length (photoperiod) can affect immune activity, thus including IgG production (Demas and Nelson 1996, 1998a, 1998b; Martin et al. 2007), in addition to FR, deer mice experienced either long or short photoperiods throughout the experiment.

\section{Methods}

Animals

Adult ( 90-d-old) male Peromyscus maniculatus bairdii were obtained from the Peromyscus Genetic Stock Center at the University of South Carolina (Columbia), housed singly in polypropylene cages at room temperature and humidity $\left(22.5^{\circ} \pm\right.$ $1^{\circ} \mathrm{C}$ and $50 \% \pm 5 \%$ relative humidity), and exposed to either $16 \mathrm{~L}: 8 \mathrm{D}$ (long day [LD]) or 8L : 16D (short day [SD]) each day (lights off at 1500 hours EST) for the entire experiment (half of the mice in each photoperiod condition). During an initial acclimation period, all mice were provided AL food (Harlan TekLad 8640; crude protein $=22 \%$, crude fat $=5 \%$, fiber $=4.5 \%)$ and filtered chlorinated tap water. Two weeks before the first KLH injection, food intake was measured for four consecutive days for each mouse, and average daily food consumption was calculated. These data were used to establish (restricted) diets to be used later. All procedures were approved by the Ohio State University Institutional Animal Care and Use Committee and comply with current National Institutes of Health guidelines for animal research and Animal Behavior Society guidelines.

\section{Experiment Progression}

Immediately before initial KLH challenge, blood $(\sim 100 \mu \mathrm{L})$ was collected from the retro-orbital sinus of each mouse into heparanized microcapillary tubes while mice were under isoflurane anesthesia. Immediately after blood collection, each mouse was injected intraperitoneally (i.p.) with $150 \mu \mathrm{g}$ KLH (CalBiochem, La Jolla, CA). After 7, 14, and $21 \mathrm{~d}$, an additional blood sample was obtained to characterize primary antibody responses. After blood collection, samples were centrifuged at 7,000 rpm for 20 min, and plasma was removed and stored at $-80^{\circ} \mathrm{C}$ until enzyme-linked immunosorbent assay (ELISA). Twenty-one days after initial KLH injection, mice were assigned randomly to AL or FR diets, which were administered for two consecutive weeks (Fig. 1). FR mice received $70 \%$ of food consumed under AL conditions; all other mice were maintained on AL food availability. Sample sizes in each group were as follows: LD, AL: 7; LD, FR: 9; SD, AL: 8; SD, FR: 8. Most mice in the FR group consumed all food provided; in the few cases when they did not, remaining food was removed and replaced with the appropriate amount of fresh food. We chose to maintain in-


Figure 1. Effects of 2-wk food restriction (FR; 70\% ad lib. [AL] intake) on body mass in Peromyscus maniculatus housed in long-day (LD; A) and short-day $(\mathrm{SD} ; B)$ photoperiods. Bars are means \pm SEM. Sample sizes in each group were as follows: LD, AL: 7; LD, FR: 9; SD, AL: 8; SD, FR: 8 . 
dividuals that did not consume food on some occasions in the experiment in an effort to perform the most conservative analysis. Body mass was measured in all individuals before FR, every $3 \mathrm{~d}$ during the FR period, and at the time of the second KLH injection. After the FR period and for the remainder of the study, all mice were returned to AL access to food. One day after FR, a blood sample was taken (as above), and secondary antibody responses to KLH were induced (30 $\mu$ g i.p.). Five days later, mice were decapitated while under deep isoflurane anesthesia, and trunk blood and spleens were collected for ELISA and flow cytometry, respectively. During all procedures and before injections or blood sampling, mice were handled and anesthetized comparably.

\section{KLH ELISA}

To measure anti-KLH IgG, we employed a modified colorimetric ELISA developed for Peromyscus (Demas and Nelson 1996). Briefly, 96-well plates were coated with KLH, and then thawed plasma samples were diluted with phosphate-buffered saline-Tween (PBS-T; $1: 200$ ), vortexed, and added to plates in duplicate. Positive (plasma samples from Peromyscus already determined to have high anti-KLH IgG titers) and negative (plasma from KLH-naive mice) controls were also added to each plate in triplicate. Plates were then sealed, incubated at $37^{\circ} \mathrm{C}$ for $3 \mathrm{~h}$, and washed with PBS-T, and then one of two secondary antibodies (both alkaline-phosphatase conjugated antimouse: IgG1 [ICN Biomedicals, Aurora, OH] and IgG2a [Serotec, Oxford]) was added to each well (dilutions: IgG1, $1: 750$; IgG2a, $1: 2,000$ ); both subclasses were measured in all samples but on different plates. Plates were again incubated $\left(37^{\circ} \mathrm{C}\right.$ for $\left.1 \mathrm{~h}\right)$ and washed with PBS-T, and then each well was treated with $p$-nitrophenyl phosphate. Exactly 20 min later, optical density (OD) of each well was read (405-nm filter; BioRad Benchmark microplate reader, Richmond, CA), and mean OD of each sample was calculated. Data analysis was performed on sample OD readings, expressed as a percentage of the positive controls on each plate. All samples were measured blind to sample identity, and mean intra- and interplate variation were $<10 \%$.

\section{Flow Cytometry}

Spleens were excised and macerated in Hanks's buffered saline solution by using a stomacher machine. The resultant cell suspension was washed via centrifugation $(600 \mathrm{~g}$ for $10 \mathrm{~min}$ at $\left.4^{\circ} \mathrm{C}\right)$, and red blood cells were lysed with buffer $\left(0.16 \mathrm{M} \mathrm{NH}_{4} \mathrm{Cl}\right.$, $10 \mathrm{mM} \mathrm{KHCO}_{3}$, and $0.13 \mathrm{mM}$ EDTA). After a second wash, cells were filtered through a 70- $\mu \mathrm{m}$ nylon mesh filter and then resuspended in CTLL RPMI 1640 (containing 0.075\% sodium bicarbonate, $1.5 \mathrm{mM} \mathrm{L}$-glutamine, and $0.00035 \%$ 2-mecraptoethanol) $+10 \%$ heat-inactivated fetal bovine serum (FBS). Cells in the preparation were enumerated using a $\mathrm{Z} 2$ particle counter (Beckman Coulter, Fullerton, CA) and adjusted to a concentration of $5 \times 10^{6}$ cells $\mathrm{mL}^{-1}$. A total of $2.5 \times 10^{5}$ cells was then incubated at $4^{\circ} \mathrm{C}$ for $45 \mathrm{~min}$ with $\mathrm{PE}$-conjugated antiIgG (polyclonal; eBioscience, San Diego, CA) and PerCPconjugated anti-B220 (clone RA3-6B2; BD Pharmingen, San Diego, CA) antibodies. Antibody labeling was performed by a standard lyse wash procedure using FACS lysing solution (BD Immunocytometry Systems, San Jose, CA) and supplemented PBS (Dulbecco's PBS without calcium or magnesium, 2\% FBS, $0.1 \% \mathrm{NaN}_{3}$ ). A total of 10,000 cells from each sample was analyzed on a dual-laser flow cytometer (FACSCalibur, BD Immunocytometry Systems) using CellQuest Pro (ver. 4.0.2) and Attractors software (ver. 3.1.0). Cells were identified on the basis of forward- and side-scatter characteristics and antibody staining. Matched isotype controls were used for both antibodies to set negative staining criteria.

\section{Data Analysis}

Before analysis, data were tested to ensure that requirements of parametric statistics were met. To compare antibody responses, ANOVA or repeated-measures ANOVA was conducted on primary and secondary responses or individual time points, with FR, photoperiod treatment, and their interaction as factors. Body mass change during and before FR was analyzed similarly. Splenic leukocyte numbers were analyzed using univariate ANOVA with the above factors. All analyses were conducted with SPSS (ver. 15) with $\alpha=0.05$.

\section{Results}

\section{Effects of FR and Photoperiod on Body Mass}

Photoperiod did not significantly affect body mass before FR (univariate $F_{1,29}=0.58, P=0.45$ ). Neither FR (repeatedmeasures $F_{5,140}=1.0, P=0.43$ ) nor photoperiod (repeatedmeasures $F_{5,140}=0.48, P=0.79$ ) affected body mass loss before the secondary antigen challenge (Fig. 1). Likewise, neither FR (univariate $F_{1,29}=1.44, P=0.24$ ) nor photoperiod (univariate $F_{1,29}=0.65, P=0.43$ ) affected body mass on the day of the second KLH challenge.

\section{Effects of FR and Photoperiod on Circulating IgG}

Mice mounted IgG1 (repeated-measures $F_{3,93}=107.5, P<$ 0.001 ) and IgG2a (repeated-measures $F_{3,93}=52.6, P<0.001$ ) primary antibody responses against KLH because anti-KLH antibody titers increased significantly over time within individuals. However, photoperiod did not affect primary responses (repeated-measures IgG1: $F_{3,93}=1.1, P=0.39$; IgG2a: $\left.F_{3,93}=0.33, P=0.80\right)$. After the primary antibody responses but before the second antigen challenge, IgG1 titer was not affected by FR (univariate $F_{1,29}=0.03, P=0.85$ ) or photoperiod (univariate $F_{1,29}=0.08, P=0.85$ ). The same was true for IgG2a; it was not affected by either FR (univariate $F_{1,29}=$ 1.9, $P=0.17$ ) or photoperiod (univariate $F_{1,29}=0.23, P=$ $0.64)$.

All mice mounted significant IgG1 (univariate $F_{1,29}=5.7$, 
$P=0.02$ ) and IgG2a (univariate $F_{1,29}=67.5, P<0.001$ ) secondary responses against $\mathrm{KLH}$, as indicated by elevated antibody titers $5 \mathrm{~d}$ after the second KLH challenge. To ascertain whether FR affected secondary antibody responses, we examined IgG1 and IgG2a titers $5 \mathrm{~d}$ after the secondary antigen challenge as well as the change in titer during this period. IgG1 titers $5 \mathrm{~d}$ after the second $\mathrm{KLH}$ injections were not influenced by FR (univariate $F_{1,29}=0.37, P=0.55$; Fig. $2 A$ ) or photoperiod (univariate $F_{1,29}=0.04, P=0.84$ ). IgG2a titers $5 \mathrm{~d}$ after the second KLH injection were also not influenced by FR (univariate $F_{1,29}=0.09, P=0.77$; Fig. $2 B$ ) or photoperiod (univariate $\left.F_{1,29}=0.09, P=0.77\right)$. Similarly, changes in IgG before the second $\mathrm{KLH}$ challenge and $5 \mathrm{~d}$ after the second challenge were not affected by treatments. IgG1 and IgG2a produced during the secondary antibody response were not affected by FR (repeated-measures IgG1: $F_{1,29}=0.05, P=0.83$; IgG2a: $F_{1,29}=3.8, P=0.06$ ) or photoperiod (repeated-measures IgG1: $F_{1,29}=0.02, P=0.89$; IgG2a: $\left.F_{1,29}=0.49, P=0.49\right)$.

\section{Effects of FR and Photoperiod on Splenic B Lymphocytes}

Mice that underwent 2 wk of FR had significantly fewer splenocytes (univariate $F_{1,29}=5.0, P=0.03$; Fig. $3 A$ ), significantly fewer $\mathrm{B} 220+$ cells (univariate $F_{1,29}=7.6, P=0.01$; Fig. $3 B$ ), and significantly fewer $\mathrm{B} 220+/ \mathrm{IgG}+$ cells (univariate $F_{1,29}=$ 4.35, $P=0.05$; Fig. 3C) compared to AL mice. Photoperiod did not significantly affect any of these cell numbers, however (total splenocytes: univariate $F_{1,29}=0.28, P=0.60 ; \mathrm{B} 220+$ cells: $F_{1,29}=0.21, P=0.65 ; \mathrm{B} 220+/ \mathrm{IgG}+$ cells: $F_{1,29}=0.01$, $P=0.90)$.

\section{Discussion}

Immunological memory results when antigen-specific B cells differentiate into long-lived, quiescent memory B lymphocytes. These memory B cells possess high-affinity receptors for specific antigens and increased IgG expression on cell membranes (relative to other isotypes). As a result, memory $\mathrm{B}$ cells produce more antibodies more rapidly during second antigen exposures (Abbas et al. 2000). Immunological memory is maintained through ongoing, low-intensity cell proliferation. If maintenance of this immune memory is costly, then the abundance of memory B cells should decrease, and subsequently, secondary antibody responses should be diminished when animals are food restricted. Previously, we demonstrated the latter (Martin et al. 2007); in this study, we document the former. Combined, significant reductions in numbers of splenocytes, splenic B lymphocytes, and splenic B lymphocytes expressing IgG and a diminution in capacity to generate IgG post-FR functionally (but indirectly) represent a cost of immunological memory in deer mice.

The above data document an effect of FR on splenic B cell populations, but the specific mechanisms producing such differences remain unidentified. One possibility involves energy availability for proliferative processes to the memory B cells
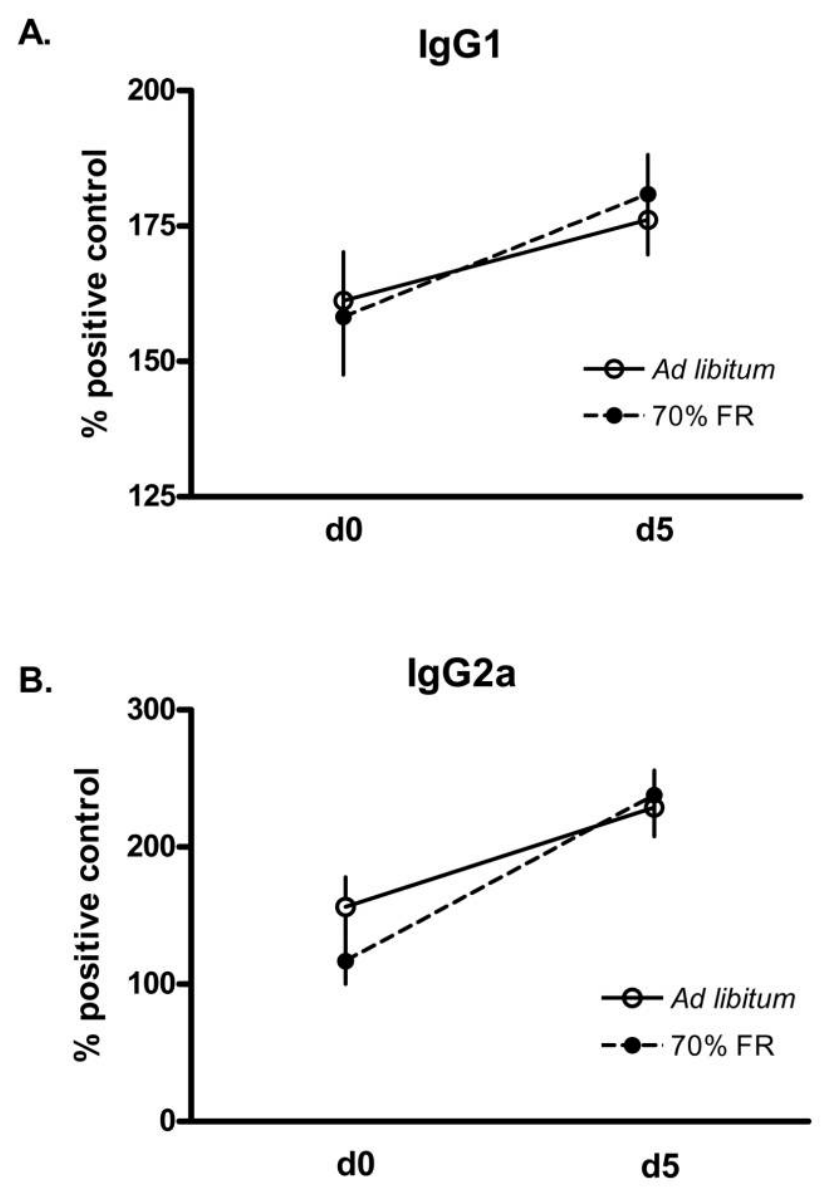

Figure 2. Effects of 2-wk food restriction (70\% ad lib. intake) on secondary antibody (IgG1 $[A]$ and $\operatorname{IgG} 2 \mathrm{a}[B]$ ) production in Peromyscus maniculatus. Bars are means \pm SEM.

themselves and/or to antigen-specific $T$ helper cells that facilitate B cell responses. Cell proliferation in general (Epel 1963) and humoral immune responses in particular (Demas et al. 2003; Bourgeon et al. 2006) are expensive, so lack of calories, fat, or protein may directly compromise memory B cell proliferation. An alternative possibility is that FR inhibited other components of the immune system, namely, the complement system, which is critical for memory B cell generation, priming, and localization (Klaus and Humphrey 1977; Klaus 1979; Cutler et al. 1998). Domestic mice lacking two complement components (C3 and C1q) exhibit abnormal B memory cell proliferation (Klaus and Humphrey 1977; Cutler et al. 1998).

FR had no differential effect on antibody isotype predominance. Two isotypes were measured in this study to determine whether FR more dramatically affected Th2- or Th1-directed immune responses (Pruett and Fan 2001), IgG1 and IgG2a, respectively. Both antibody variants increased after primary and secondary KLH challenges, but neither the subclass titer $5 \mathrm{~d}$ following the secondary KLH challenge nor the magnitude of secondary antibody responses (change day $0-$ day 5) of each subclass differed significantly between FR and AL mice. Con- 
A. splenocytes

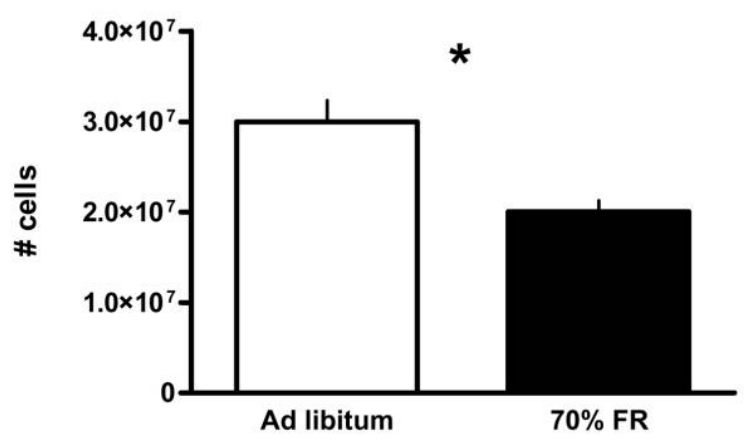

B.

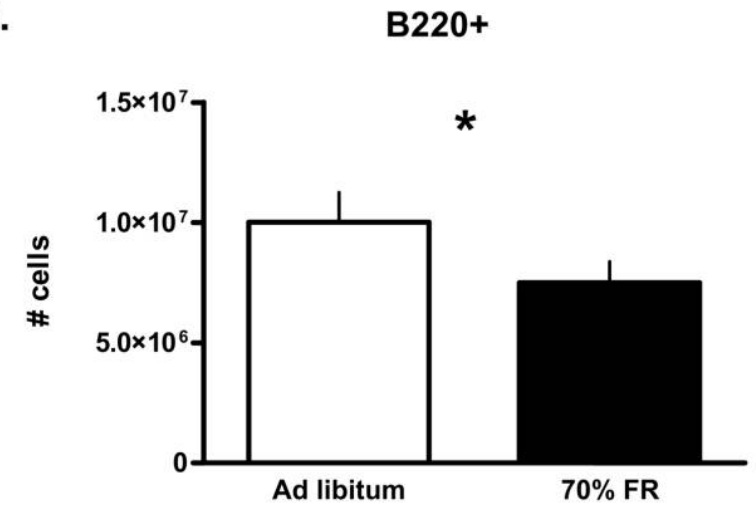

C.



Figure 3. Effects of 2-wk food restriction (FR; 70\% ad lib. intake) on splenic IgG-producing cells in Peromyscus maniculatus. A, Total splenocytes; $B$, B lymphocytes (B220+); and $C$, IgG-producing B lymphocytes $(\mathrm{B} 220+/ \mathrm{IgG}+)$. Bars are means + SEM; asterisks indicate significant effect of FR $(P<0.05)$.

servatively, this outcome may indicate that $70 \%$ FR effects on IgG production in deer mice are more modest than previously indicated (Martin et al. 2007). On the other hand, effects of FR on KLH-specific IgG did not manifest until $7 \mathrm{~d}$ after the secondary challenge in the previous study (Martin et al. 2007).
Spleens in the current study were collected at day 5 to ensure that any effects of FR on memory B cells could be detected before mice could compensate by refeeding when returned to an AL diet. For these reasons, future studies should replicate our work and quantify antibodies and memory B cell numbers after a longer intervals post-secondary challenge.

We expect that our results are relevant in natural contexts. Oftentimes, compensation for food scarcity may be achieved in the wild by preferentially investing resources in only those physiological processes critical for immediate survival, which likely would not include maintenance of immune memory. This phenomenon motivated the day length manipulation component of the study. Photoperiod is a salient, error-free cue that organisms use to adjust their phenotypes to prevailing or impending changes in environment (Prendergast et al. 2001). Because photoperiod extensively affects rodent immune defenses (Nelson 2004), we predicted that prior natural selection for appropriate resource allocation to immunity versus other physiological processes would have also influenced how photoperiod and FR affected splenic B cell numbers, but this was not the case. Instead, our results indicate that immediate availability of food directly affected B cell population sizes; deer mice appear unable to prime themselves for FR, at least when restricted to $70 \%$ of their AL diet. Perhaps during times of low energy demands, they and other wild organisms favor less costly types of immune defenses (Lochmiller and Deerenberg 2000), but this possibility requires further study.

One final aspect of this study that must be emphasized is its potential relevance to human health. Infections are more frequent and tend to be chronic in malnourished children (Cunningham-Rundles et al. 2005), and the consequences of some infections are dramatically (e.g., pneumonia, bacterial and viral diarrhea, measles, and tuberculosis) or moderately (e.g., influenza and HIV) magnified by malnutrition (Chandra 1999). For some infections, malnutrition may compromise the ability of individuals to produce antibodies against vaccines. Just after the drought of 2000 in the Gombe region of Ethiopia, field efficacy of measles vaccine (an index of the ability of vaccine to prevent measles in vaccinated versus unvaccinated individuals) was only $66.3 \%$; under ideal conditions, a similar vaccination regime produces $85 \%$ efficacy (Talley and Salama 2003). Other factors may also have mitigated the low success rate in that study, but work on historic epidemics (e.g., whooping cough in eighteenth- and nineteenth-century Liverpool) suggests that human mortality to infection is often strongly influenced by food availability (Duncan et al. 1996). Likewise, anorectic individuals in modern populations suffer from decreased circulating IgG and compromised $\mathrm{T}$ cell coordination of B cell activities (Allende et al. 1998). In many cases, refeeding can eliminate such immune deficiencies.

In most of these studies and ours, the specific contribution of calories versus protein versus micronutrients (Chandra 1999) was unidentified but would be worthy of future study. Further, it would be useful to determine to what extent leptin, a regulatory peptide secreted by adipose tissue (Lord et al. 1998), 
orchestrates decreases in memory B cell numbers and subsequent IgG production. Previous work in another rodent species indicated that the suppressive effects of fat tissue ablation on antibody production could be reversed by leptin treatment (Demas and Sakaria 2005). Finally, it would be intriguing to determine how FR affects proliferation of new memory B cells versus maintenance of previously generated $B$ cell populations (Demas and Nelson 1998a; Buchanan et al. 2003; Gasparini et al. 2006). At present, it is unknown whether FR inhibited one or both processes; imposing FR without administering second KLH challenges could reconcile these alternatives.

\section{Acknowledgments}

We thank Stephanie Kidder, Eric Johnson, Jonathan Wade, and Zachary Weil for help with animal care, assays, and data discussion. This work was supported by National Institutes of Health grants MH 57535 and MH 66144 and by National Science Foundation grant IBN 04-16897 to R.J.N. K.J.N. was supported by National Research Service Award T32 AI055411.

\section{Literature Cited}

Abbas A.K., A.H. Lichtman, and J.S. Pober. 2000. Cellular and Molecular Immunology. Saunders, New York.

Allende L.M., A. Corell, J. Manzanares, D. Madruga, A. Marcos, A. Madrono, A. Lopez-Goyanes, et al. 1998. Immunodeficiency associated with anorexia nervosa is secondary and improves after refeeding. Immunology 94:543-551.

Bonneaud C., J. Mazuc, G. Gonzalez, C. Haussy, O. Chastel, B. Faivre, and G. Sorci. 2003. Assessing the cost of mounting an immune response. Am Nat 161:367-379.

Bourgeon S., J. Martinez, F. Criscuolo, Y. Le Maho, and T. Raclot. 2006. Fasting-induced changes of immunological and stress indicators in breeding female eiders. Gen Comp Endocrinol 147:336-342.

Buchanan K.L., K.A. Spencer, A.R. Goldsmith, and C.K. Catchpole. 2003. Song as an honest signal of past developmental stress in the European starling (Sturnus vulgaris). Proc R Soc B 270:1149-1156.

Chandra R.K. 1999. Nutrition and immunology: from the clinic to cellular biology and back again. Proc Nutr Soc 58:681683.

Cunningham-Rundles S., D.F. McNeeley, and A. Moon. 2005. Mechanisms of nutrient modulation of the immune response. J Allergy Clin Immunol 115:1119-1128.

Cutler A.J., M. Botto, D. van Essen, R. Rivi, K.A. Davies, D. Gray, and M.J. Walport. 1998. T cell-dependent immune response in $\mathrm{Clq}$-deficient mice: defective interferon gamma production by antigen-specific T cells. J Exp Med 187:17891797.

Demas G.E., D.L. Drazen, and R.J. Nelson. 2003. Reductions in total body fat decrease humoral immunity. Proc R Soc B 270:905-911.
Demas G.E. and R.J. Nelson. 1996. Photoperiod and temperature interact to affect immune parameters in adult male deer mice (Peromyscus maniculatus). J Biol Rhythms 11:94102.

1998a. Photoperiod, ambient temperature, and food availability interact to affect reproductive and immune function in adult male deer mice (Peromyscus maniculatus). J Biol Rhythms 13:253-262.

. 1998b. Short-day enhancement of immune function is independent of steroid hormones in deer mice (Peromyscus maniculatus). J Comp Physiol B 168:419-426.

Demas G.E. and S. Sakaria. 2005. Leptin regulates energetic trade-offs between body fat and humoural immunity. Proc R Soc B 272:1845-1850.

Derting T.L. and S. Compton. 2003. Immune response, not immune maintenance, is energetically costly in wild whitefooted mice (Peromyscus leucopus). Physiol Biochem Zool 76:744-752.

Duncan C.J., S.R. Duncan, and S. Scott. 1996. Whooping cough epidemics in London, 1701-1812: infection dynamics, seasonal forcing and the effects of malnutrition. Proc R Soc B 263:445-450.

Epel D. 1963. The effects of carbon monoxide inhibition on ATP level and the rate of mitosis in the sea urchin egg. J Cell Biol 17:315-319.

Fair J.M. and O.B. Myers. 2002. The ecological and physiological costs of lead shot and immunological challenge to developing western bluebirds. Ecotoxicology 11:199-208.

Gasparini J., A. Roulin, V.A. Gill, S.A. Hatch, and T. Boulinier. 2006. In kittiwakes food availability partially explains the seasonal decline in humoral immunocompetence. Funct Ecol 20:457-463.

Ilmonen P., T. Taarna, and D. Hasselquist. 2000. Experimentally activated immune defence in female pied flycatchers results in reduced breeding success. Proc R Soc B 267:665-670.

Klasing K.C. 2004. The costs of immunity. Acta Zool Sin 50: 961-969.

Klasing K.C. and C.C. Calvert. 1999. The care and feeding of an immune system: an analysis of lysine needs. Pp. 253-264 in G.E. Lobley and A. White, eds. Protein Metabolism and Nutrition. Wageningen Academic, Wageningen.

Klaus G.G.B. 1979. Generation of memory cells. III. Antibody class requirements for the generation of B-memory cells by antigen-antibody complexes. Immunology 37:345-351.

Klaus G.G.B. and J.H. Humphrey. 1977. The generation of memory cells. I. The role of $\mathrm{C} 3$ in the generation of $\mathrm{B}$ memory cells. Immunology 33:31-40.

Lee K.A. 2006. Linking immune defenses and life history at the levels of the individual and species. Integr Comp Biol 46: 1000-1015.

Lochmiller R.L. and C. Deerenberg. 2000. Trade-offs in evolutionary immunology: just what is the cost of immunity? Oikos 88:87-98.

Lord G.M., G. Matarese, L.K. Howard, R.J. Baker, S.R. Bloom, and R.I. Lechler. 1998. Leptin modulates the T-cell immune 
response and reverses starvation-induced immunosuppression. Nature 394:897-901.

Martin L.B., K.J. Navara, Z.M. Weil, and R.J. Nelson. 2007. Immunological memory is compromised by food restriction in deer mice, Peromyscus maniculatus. Am J Physiol 292: R316-R320.

Martin L.B., A. Scheuerlein, and M. Wikelski. 2003. Immune activity elevates energy expenditure of house sparrows: a link between direct and indirect costs? Proc R Soc B 270:153158.

Martin L.B., Z.M. Weil, and R.J. Nelson. 2006. Refining approaches and diversifying directions in ecoimmunology. Integr Comp Biol 46:1030-1039.

- 2007. Immune defense and reproductive pace of life in Peromyscus mice. Ecology 88:2516-2528.

- 2008. Seasonal changes in vertebrate immune activity: mediation by physiological trade-offs. Philos Trans R Soc B 363:321-339.

Nelson R.J. 2004. Seasonal immune function and sickness responses. Trends Immunol 25:187-192.

Prendergast B.J., A.K. Hotchkiss, S.D. Bilbo, and R.J. Nelson.
2004. Peripubertal immune challenges attenuate reproductive development in male Siberian hamsters (Phodopus sungorus). Biol Reprod 70:813-820.

Prendergast B.J., L.J. Kriegsfeld, and R.J. Nelson. 2001. Photoperiodic polyphenisms in rodents: neuroendocrine mechanisms, costs, and functions. Q Rev Biol 76:293-325.

Pruett S.B. and R.P. Fan. 2001. Quantitative modeling of suppression of IgG1, IgG2a, IL-2, and IL-4 responses to antigen in mice treated with exogenous corticosterone or restraint stress. J Toxicol Environ Health 62:175-189.

Råberg L., M. Vestberg, D. Hasselquist, R. Holmdahl, E. Svensson, and J.A. Nilsson. 2002. Basal metabolic rate and the evolution of the adaptive immune system. Proc R Soc B 269: 817-821.

Talley L. and P. Salama. 2003. Short report: assessing field vaccine efficacy for measles in famine-affected rural Ethiopia. Am J Trop Med Hyg 68:545-546.

Verhulst S., S.J. Dieleman, and H.K. Parmentier. 1999. A tradeoff between immunocompetence and sexual ornamentation in domestic fowl. Proc Natl Acad Sci USA 96:4478-4481. 